\title{
Medicina, educação e gênero: as diferenciações sexuais do suicídio nos discursos médicos do século XIX
}

\section{Medicine, education and gender: suicide sexual differences in the XIX century medical discourses}

\author{
Fábio Henrique Lopes*
}

\begin{abstract}
RESUMO
Por meio deste artigo, analiso as diferenciações sexuais, constantes e recorrentes em discursos médicos do século XIX, entre o suicídio cometido por homens daquele cometido por mulheres. Busco a base utilizada para sustentar tal diferenciação, problematizo a possibilidade de pensar a diferença entre um modo masculino e um outro feminino de se suicidar, destacando, nesse processo normatizador, o papel atribuído à Educação e sua tarefa preventiva.

Palavras-chave: educação; suicídio; gênero; discurso médico.
\end{abstract}

\begin{abstract}
By means of this article, constant and repeated sexual differences in XIX century medical discourses are analysed, between suicide committed by men and that one comitted by women. I'm seeking the basis used in order to support such difference and questioning the possibility of thinking about the difference between a male and a female gender of committing suicide, standing out, in this normative process, the role attributed to Education and its preventive task.

Key-words: education; suicide; gender; medical discourse.

* Doutor em História - Unicamp. Professor da Faculdade de História, Puc-Camp, e do Departamento de História do IMES/FAFICA. E.mail: lopesfh@yahoo.com.
\end{abstract}




\section{Introdução}

Em meio à multiplicidade de teorias, causas, meios e conceitos desenvolvidos e divulgados em estudos médicos sobre o suicídio, ao longo do século XIX, médicos brasileiros e franceses ajudaram a construir as chamadas diferenças entre "os sexos". Modelaram o "homem" e a "mulher" segundo uma interpretação específica, hierarquizadora de suas constituições físicas e biológicas.

Ao focalizar essa prática, busco problematizar as possíveis diferenças entre o suicídio cometido por um homem e o cometido por uma mulher, interrogando as constituições das identidades consideradas próprias aos homens e às mulheres, ajudando a perceber a diferença entre o que era e o que deveria ser considerado pertencente ao campo do "masculino" ou do "feminino".

Para interrogar essa criação, utilizo o gênero como categoria de análise para apontar a não-naturalidade do feminino e do masculino na construção cultural e social dessas identidades, desnaturalizando-as. Para tal empreitada, utilizo algumas abordagens: em primeiro lugar, o estudo de Joan Scott sobre o gênero como "categoria útil de análise histórica"; em seguida, os de Rachel Soihet, Margareth Rago, entre outros estudos. Segundo estas pesquisadoras, o termo gênero tem sido usado para teorizar a questão da diferença sexual, desafiando antigas concepções de que o biológico seria determinante. A palavra indica rejeição ao determinismo biológico implícito no uso de termos como sexo ou diferença sexual. Além do mais, o gênero sublinha também o aspecto relacional entre mulheres e homens, sugerindo que nenhuma compreensão pode existir considerando-os totalmente em separado. Assim, é possível levar em conta a dimensão sexualizada ou "engendrada" (engendered) das práticas sociais e das experiências em torno do suicídio.

Dessa maneira, busco interrogar as idéias, argumentos e conceitos transformados em práticas, por meio dos discursos médicos, para classificar determinadas atitudes como "próprias" do referencial masculino e outras, do feminino. Evidencio também a construção da categoria homem/ mulher como oposição binária e a tendência de achar que ela se auto-reproduz, estabelecida sempre da mesma maneira, universalmente. Exploro ainda a constituição do campo masculino e do feminino e quais seus papéis na tematização do suicídio. 
Para tal, divido a abordagem médica em duas séries temáticas. A primeira, educação dirigida e diferenciada. A última, casamento, celibato e relações sexuais. Porém, antes de tudo, é necessário destacar que o suicido é, pelo menos ao longo do século XIX, um tema masculino. Foram os homens, brancos e burgueses, que se dedicaram ao estudo do tema. Assim, as próprias diferenças sexuais que são constituídas em discursos médicos brasileiros e franceses sobre o suicídio, e que se expandem social e culturalmente, são territórios masculinos, pois foram criados por homens, mais especificamente pelos homens da ciência, conferindo status de verdade masculina e científica, ou seria melhor dizer, verdade científica masculina.

A constatação acima sugere que todos os conceitos criados, os modos de pensar o suicídio, as identidades construídas (e que deveriam ser respeitadas) e as diferenças sexuais constituídas em tais trabalhos médicos são, em primeiro lugar, excludentes, porque deixam de lado tudo e todos que escapam deles; em seguida, territorializantes, pois apresentam uma tendência que procura cercar a multiplicidade de tipos e sujeitos que se suicidam, classificando-os e catalogando-os, para criar territórios masculinos de produção de saber, conhecimento e de verdades; e, por fim, criadores de identidades sexuais, porque procuram uma origem biológica para as diferenças sexuais, indicando a existência de uma possível "essência biológica pré-determinada" para pensar o "homem" e a "mulher".

\section{Educação dirigida e diferenciada}

Produto, efeito e construtor da modernidade, o saber médico social se dedicou ao estudo e análise de temas ligados à Educação. Se hoje é possível perceber imbricações e entrecruzamentos entre os campos médico e pedagógico, essa relação emergiu, no Brasil, no século XIX. A esse respeito, Stephanou (1999, p. 129) argumenta que "pelo menos desde o final do século XIX, discutia-se que Educação e saúde seriam as investidas mais importantes para 'salvar o país' do atraso, da degeneração, da catástrofe." Assim, da aproximação e trocas entre esses dois campos do saber, não só a atuação educativa e saneadora da medicina foi reforçada, como o próprio pensar a Educação foi gerido e instituído. 
Mas referente aos discursos médicos sobre o suicídio, como a Educação foi tematizada? Em que medida ela pode ocasionar ou impedir o suicídio?

A Educação que não era "corretamente dirigida" foi muito citada pelos médicos como causa de desordens mentais e de suicídio. Além de determinar preceitos de higiene e saúde, ela deveria fundamentar e reforçar os papéis próprios aos homens e às mulheres em sociedade. Por isso, a educação deveria, segundo tais médicos, ser diferenciada de acordo com o sexo. Meninos e meninas precisavam receber tratamento condizente com sua natureza biológica.

Buscava-se, por exemplo, que os meninos, desde os primeiros tempos, se afastassem de tudo que pudesse efeminá-los, que pudesse deixá-los com características consideradas "próprias" das meninas. Nesse sentido, Torres (1843, p. 5) argumenta que:

A experiência quotidiana mostra que uma educação efeminada torna os meninos impertinentes, irascíveis e imperiosos em seus desejos: costumados desde a infância a ser prevenidos em todas as suas vontades e satisfeitos em seus caprichos, quando adultos, a menor contrariedade, o mais insignificante infortúnio os torna suicidas.

Por outro lado, o médico sugeria uma especial precaução com esses meninos, pois não era por evitar excesso de cuidados e a satisfação dos desejos que se poderia agir de maneira oposta, ou seja, com agressividade, sem prudência ou moderação. A esse respeito ele defende que:

Dois extremos igualmente perigosos na educação dos meninos devem-se evitar. A vítima de nímia severidade contrai quase sempre um humor frio e concentrado, predispõe-se para a melancolia e a influência desta causa é de certo mais funesta. As repreensões amargas, os castigos desumanos e ameaças contínuas exasperam o caráter, produzem inclinações perversas e levam não poucas vezes a infeliz mocidade à alienação mental, caracterizadas pela tendência ao suicídio (TORRES, 1843, p. 5-6). 
Mas, e as meninas? Se os meninos deviam ser "sabiamente" educados para afastarem-se de tudo que diz respeito ao campo do feminino, como as meninas deveriam ser educadas? Elas receberiam as mesmas "lições" que os meninos? Quais as finalidades de as educarem? Estariam à mercê de mesmas influências "nocivas" que podiam levar os meninos ao suicídio? Vejamos o que Dr. Torres sugere sobre a educação feminina:

Mais digna de compaixão é ainda a sorte das míseras mulheres, e aqui não podemos deixar de lastimar nossas jovens patrícias, cujos pais e maridos, descuidando-se de enriquecer-lhes a inteligência, procuram-lhes músicas, bailes, teatros, danças como passa-tempos os mais próprios de excitarlhes a vivacidade, e prodigalizando nestas futilidades tempo e fortuna, deixam à sedução o cuidado de formar-lhes o coração. Nem se diga que somos exagerados quando asseveramos que tal educação deve resultar de outros inconvenientes a propensão ao suicídio (TORRES, 1843, p. 5).

Note-se que, segundo o médico, os pais e maridos são os responsáveis por "enriquecer" a inteligência não só de suas filhas como de suas esposas. Partiria, assim, do homem - sujeito visto como racional, forte e superior - o comando e o controle do grau de inteligência a ser adquirido e/ou aperfeiçoado pela filha e/ou mulher.

Estas filhas, mulheres e esposas, por freqüentarem bailes, teatros e danças, estariam, principalmente aquelas de família burguesa que tinham condições financeiras para isso, sendo influenciadas por sentimentos, paixões e, inclusive, perversões geradas nesses ambientes, contra os quais, muitas vezes, a educação sabiamente dirigida pelo homem nada podia. Como exemplo, Dr. Torres cita o caso de uma mulher que sentira em três épocas diferentes violentas comoções do sistema nervoso, seguidas de tendência ao suicídio, ocasionadas por duas ou três árias da ópera Nina (TORRES, 1843 , p. 5).

Uma outra diferença muito observada sobre a educação diz respeito aos exercícios físicos. A predominância de uma educação exclusivamente física poderia alterar a sensibilidade feminina. Segundo o médico francês J. A. Durand (1816), esse excesso de exercício físico pode provocar, inclusive, reversão da "ordem natural", o que resultaria mulheres apresentan- 
do a constituição muscular do outro sexo. As "femmes hommasses" desenvolveriam, por meio da educação dirigida ao físico, um sistema muscular que não lhe era "próprio" e "natural". Lembre-se que, de acordo com o pensamento médico da época, os músculos firmes e rígidos são os masculinos e não os femininos.

Mas o suicídio ocorreria somente entre aqueles que não gozaram de uma educação devidamente dirigida e diferenciada?

Dr. Vianna responde que não. Segundo ele, principalmente as mulheres, que por sua constituição se entregam mais facilmente às impetuosidades dos desejos, podem se suicidar mesmo tendo gozado de uma boa educação. De acordo com ele:

(...) algumas vezes mesmo de uma educação sabiamente dirigida têm-se visto moças inflamadas de amor, cedendo em fim à impetuosidade dos desejos, que sem cessar as importunam, cair em um estado de melancolia profunda procurar a solidão e o silêncio, para se entregarem livremente à sua dor, e a seu desespero e no excesso de sua perturbação levar sobre si mesmas a mão suicida (VIANNA, 1842, p. 16).

Recorrer a Peter Gay (1988, p. 158-159) nesse momento pode ser útil, principalmente para elucidar algumas questões sobre a educação das mulheres, em especial a educação superior, porque o autor analisa, em vários momentos de sua obra, muitos discursos que se dedicaram ao tema. Segundo ele, os argumentos daqueles que se posicionavam contra a educação universitária das mulheres "iam da sutileza à grosseria, de uma fala de tato condescendente à rejeição sumária e rude". Assim, argumentava-se que "as mulheres não tinham necessidade de uma formação superior; não tinham como tirar proveito dela; poderiam não sobreviver a ela".

De acordo com Gay, médicos e intelectuais de várias áreas questionavam, no século XIX, o que eles chamavam de abandono por parte das mulheres "da verdadeira vocação". Mas o autor destaca que, em sua maioria, são homens que colocavam em xeque a instrução das mulheres. Luta-

1 Segundo Le Nouveau Petit Robert. Dictionnaire alphabétique et analogique de la langue française. Nouvelle édition du Petit de Paul Robert. Paris: Dictionnaires Le Robert, 2000, p.1228, o adjetivo Hommasse é assim definido "qui ressemble à um homme par l'allure, les manières, en parlant d'une femme". 
vam pela manutenção de seus papéis e de seus espaços masculinos, contra um perceptível "clamor das mulheres". É nesse sentido que tais discursos devem ser analisados, porque afirmavam que a educação arruinaria a saúde das mulheres, principalmente quanto à sua nobre capacidade de reprodução da espécie. Além do mais, acreditava-se que a força vital e construtiva das mulheres deveria localizar-se em seus "ovários e acessórios" e não em seu cérebro.

No lugar de pretender freqüentar as universidades, exercer profissões consideradas masculinas e estar presente em espaços públicos, também considerados como próprios dos homens, a mulher deveria se preocupar com a vida conjugal, com a procriação, a educação dos filhos e manutenção e cuidado com o espaço privado. Uma educação que as levasse à esfera, práticas e comportamentos considerados como próprios do campo masculino era vista como nociva à saúde da mulher, por não respeitar sua natureza biológica.

Com a mesma sensibilidade, Margareth Rago (1997, p. 63-64) também observou que a educação dirigida às mulheres visava prepará-las não para a vida profissional, mas sim para exercer sua função essencial, ou seja, a carreira doméstica. Mesmo quando elas começaram a invadir o cenário urbano do trabalho, o movimento operário, liderado por homens, tratou de fortalecer a intenção disciplinadora de deslocamento da mulher da esfera pública do trabalho para o espaço privado do lar. Assim, demandaram seu retorno ao campo que o poder masculino lhe circunscreveu: o espaço da atividade doméstica e o exercício da "função sagrada" da maternidade.

A preocupação com a educação que deveria ser ministrada aos homens e às mulheres permitiu que outros temas fossem privilegiados pelo discurso médico. Assim, o casamento, o celibato e as relações sexuais foram focalizados na tentativa de melhor compreender o suicídio.

\section{Casamento, celibato e relações sexuais}

De que maneira o casamento, o celibato e as relações sexuais poderiam provocar ou impedir os casos de suicídio? Como essas questões foram desenvolvidas e respondidas por aqueles que se dedicavam à temática? 
A esse respeito, Dr. Vianna argumenta que o casamento é um pacto solene instituído para que os dois sexos possam satisfazer suas necessidades naturais, socorrerem-se mutuamente durante o curso da vida, perpetuar a espécie e permitir a existência e felicidade dos filhos, que devem nascer desta união (1842, p. 9). Vale notar que, para essa concepção médica e burguesa, um sólido ambiente familiar, um lar acolhedor, filhos educados e esposa dedicada ao marido, considerada sua companheira na vida social, são considerados um verdadeiro tesouro (D'INCAO, 2001, p. 224225). Esse ambiente proporcionado pelo casamento sadio e normatizado agiria como um meio profilático e curativo de várias doenças, inclusive as mentais. Assim, é possível perceber que, para esse médico, e segundo uma ótica masculina, o casamento é uma importante arma contra os distúrbios mentais e, por isso, contra o suicídio.

O casamento seria, assim, a realização definitiva e absoluta dos papéis sociais, sexuais e naturais destinados a homens e a mulheres, muitos dos quais definidos historicamente pela educação. $\mathrm{O}$ homem, envolvido com as responsabilidades de chefe da família, marido e pai, não se entregaria tão facilmente ao suicídio, não preferiria a morte à vida por saber que sua família - mulher e filhos — depende dele. Seus deveres como "pai" e "marido" apontam na direção de ganhar dinheiro para o sustento da família. A mulher, por sua vez, ocupando-se de suas tarefas de "esposa-dona-decasa-mãe-de-família" (RAGO, p. 61-116), ou seja, ocupada com o cultivo da domesticidade, dos deveres de ser esposa, tendo ainda que cumprir sua finalidade reprodutora e, em seguida, responsabilizar-se dos cuidados e supervisão da educação dos filhos, afastar-se-ia do suicídio por respeitar e cumprir o que lhes era esperado (D'INCAO, 2001, p. 229-237 e HAUVILLER, 1899).

Segundo o pensamento médico da época, com a satisfação, socorro e cumprimento das "obrigações naturais", a ordem - social, familiar e sexual - seria mantida; as perversões, controladas e as paixões, dominadas. Por outro lado, mas seguindo o mesmo raciocínio, o celibato era visto como risco constante de doenças, morte e suicídio entre os solteiros.

Por não constituírem família, por viverem relações sexuais ilícitas, fora do casamento, por freqüentarem lugares de tolerância para saciar seus desejos, por viverem fora da ordem natural, por desperdiçarem seus espermas e por se entregarem aos excessos sexuais, os solteiros estariam propícios ao suicídio muito mais do que os homens casados. As mulheres solteiras, por recusarem a imagem de mãe ideal, por não cumprirem com o papel que a sociedade lhes destinava e por recusarem a dádiva de participarem da 
divina função de preservação da espécie, poderiam mais facilmente pôr fim a seus dias pelas próprias mãos. Segundo a historiadora Magali Engel (2001, p. 338), de acordo com a perspectiva médica, a maternidade constituía um dos remédios mais eficazes - senão o mais eficaz — para evitar ou curar as moléstias femininas, em especial, acrescento, as mentais e o suicídio. Isso porque, ainda segundo essa historiadora, as origens de muitos dos distúrbios mentais encontram-se estritamente vinculadas ao fato de terem sempre se manifestado com a recusa radical em cumprir a função materna, naturalmente destinada a todas as mulheres:

A maternidade era vista como a verdadeira essência da mulher, inscrita em sua própria natureza. Somente através da maternidade a mulher poderia curar-se e redimir-se dos desvios que, concebidos ao mesmo tempo como causa e efeito da doença, lançavam-na, muitas vezes, nos lodos do pecado. Mas para a mulher que não quisesse ou não pudesse realizá-la aos olhos do médico, um ser físico, moral ou psiquicamente incapaz não haveria salvação e ela acabaria, cedo ou tarde, afogada nas águas turvas da insanidade (ENGEL, 2001, p. 338).

Ainda sobre o caso das mulheres solteiras, Dr. Vianna destaca, ao longo de todo seu trabalho, que o estado de celibato influi de tal maneira no desenvolvimento das alterações completas do órgão do pensamento que elas podem, por isso, se entregar ao suicídio. Por não cumprirem suas obrigações de procriação e por não satisfazerem seus apetites sexuais, as mulheres solteiras estariam mais próximas do suicídio do que os homens.

Nesse sentido, Dr. Albuquerque (1858, p. 15-16) sugere que tanto o celibato como a viuvez devem ser encarados como causas predisponentes de monomanias suicidas. Por não possibilitarem a plena realização social e sexual, tais estados produziriam ou permitiriam o suicídio. Classificado como determinante moral, o desejo não satisfeito da união dos sexos, ao lado do ódio, ciúme, exaltação da imaginação produzida por espetáculos, leituras, sociedades ou conversações, desgostos e contrariedades domésticas, exerceria influência notável sobre as funções nervosas, dando lugar ao desenvolvimento de várias monomanias. Note-se que esses dois médicos sugerem em seus estudos que a mulher nessas condições estaria arruinando sua saúde e colocando em risco o fim último de sua existência: a reprodução da espécie.

Muito próximo desta compreensão, o estudo de Dr. Barreto, sobre as enfermidades dos homens de letras, sugere que esses homens que se entregam às vigílias, meditações, letras e, principalmente, à solidão, precisam tomar cuidado com as secreções e excreções. 
Por assim pensar, o facultativo alerta que os homens não devem reter por muito tempo a urina e não podem desperdiçar a saliva, necessária para uma boa e fácil digestão. Quanto às "matérias fecais", o ilustríssimo médico adverte que elas podem produzir duas espécies de males aos homens: diarréia, que pode, se for habitual, produzir o emagrecimento, frouxidão geral e a enervação das forças físicas e morais, ou podem ainda produzir constipação, motivo, segundo ele, de um grande número de incômodos provenientes da demora prolongada das fezes no canal intestinal.

Após deter-se no estudo das influências de tais secreções e excreções, o passo seguinte foi o de analisar os efeitos da retenção do "licor espermático". Em suas palavras, "a secreção do licor espermático oferece um grande número de males, ou quando retida, ou quando feita freqüentemente. A retenção prolongada produz uma espécie de inflamação dos órgãos geradores" (BARRETO, 1841, p. 27-28).

Assim, os solitários homens das letras corriam os riscos causados por uma vida sexual não pautada pelos padrões "normais" e "naturais" que o casamento propiciaria. Mas os malefícios seriam maximizados em "pessoas ardentes" porque, de acordo com o mesmo Dr. Barreto, em tais pessoas a retenção prolongada pode produzir espasmos, a hipocondria e mesmo a mania erótica, por agir diretamente sobre o cérebro.

Por outro lado, a evacuação muito freqüente oferecia a tais homens alterações físicas e morais. Isso porque, segundo sua concepção, ela dispõe para as afecções nervosas, permite desarranjos das funções cerebrais, torna o pensamento tardio e lânguido, enfraquece a memória e extingue a imaginação. Não conseguindo preservar sua saúde, tais homens podem apresentar tendência terrível ao suicídio.

Assim, é possível observar que a masturbação masculina e a feminina são apresentadas como nocivas à vida, porque alteram o estado de saúde de seu praticante, enfraquecendo sua resistência física e moral, e à sociedade, porque pressupõe relações sexuais sem a finalidade reprodutora.

Nesse sentido, o casamento é visto como uma instituição higiênica, como arma poderosa contra o suicídio. Para o médico francês Villete (1825, p. 15-22), em sua tese $D u$ suicide, o homem casado tem um coração que está sempre aberto aos prazeres puros e inocentes porque encontra satisfação nos braços puros de uma esposa casta e virtuosa, diferente do homem solteiro que se perde na imoralidade. Este homem casado pode até ser abatido por desgostos, tristezas e sérias dificuldades impostas pela vida, mas será sempre amparado pela esposa, fiel companheira que saberá com ele dividir os sofrimentos e as dificuldades. Mas por outro lado, por contar 
com a presença revigorante da esposa, deverá a favor dela e de seus filhos permanecer vivo e nunca optar pelo suicídio. Dele, homem, depende a sobrevivência de sua família.

Temos, assim, todo o quadro referencial de gênero sendo constituído historicamente, servindo de base, mas também por ela afetada, para a constituição e proliferação de signos de masculinidade e feminilidade.

\section{Explicando um paradoxo}

Depois de tudo o que foi apresentado e analisado, seria possível compreender as razões de as mulheres se suicidarem mais do que os homens. Se o homem é, de acordo com a discursividade médica, superior à mulher, se é mais acostumado a pensar, raciocinar e discernir, se é mais forte, mais apto à vida social e muito mais resistente às vicissitudes da vida, poderíamos entender o porquê de ele se suicidar menos. Se as mulheres são fracas, débeis, limitadas, sentimentais, emotivas e frívolas, seria até mesmo "óbvio" e "natural" elas se suicidarem em maior número. Contudo, os dados empíricos revelam exatamente o oposto. Elas se suicidam menos do que os homens!

Se os médicos têm razão, se o homem é superior à mulher, por que elas se suicidam muito menos do que eles? Quais as respostas desses estudiosos? Como explicar esse paradoxo?

As respostas remetem, uma vez mais, à inferioridade das mulheres. Pelo fato de serem consideradas fracas e sentimentais, não teriam a coragem necessária para pôr fim a seus dias. Por outro lado, o homem, tão corajoso e decidido, entregar-se-ia à morte mais facilmente. Elas teriam horror ao sangue e se preocupariam com a aparência física após o suicídio; eles, naturalmente preocupados com questões mais esclarecidas, não se importariam tanto com a fisionomia do corpo após a morte. Elas seriam pouco acessíveis à intemperança, fonte de todo o mal para os homens, e, em vez de se suicidar, tornam-se alienadas e/ou loucas, mas sem propensão ao suicídio.

Infelizmente, os médicos brasileiros não utilizavam dados estatísticos em suas teses escritas no século XIX, o que acontecerá somente no século XX. Por esta razão, é impossível saber com certeza em que medida os 
homens brasileiros se suicidavam mais do que as mulheres ou mesmo definir com precisão qual o porcentual de suicídios cometidos por homens e por mulheres. A maioria desses profissionais da saúde apenas concorda com a superioridade dos casos de suicídio masculino ao longo do século XIX no Brasil. Em compensação, os médicos franceses, muitos deles conhecidos e citados pelos brasileiros, desenvolviam a fundo essa questão.

A esse respeito, em 1851, o médico francês Daumas (1851, p. 18-26) explica que as mulheres, por possuir constituição mais delicada, têm o triste privilégio de ser mais vulneráveis às doenças mentais do que os homens; entretanto o suicídio é menos freqüente entre elas. Isso se explicaria, segundo o doutor francês, pela moleza e fraqueza de caráter e pela "natural" timidez.

Assim, a inteligência, ousadia e ímpeto, características do masculino, representariam uma armadilha contra a vida do homem. Estes, constantemente envolvidos em grandes trabalhos intelectuais, por concentrar toda sua força, inteligência, pensamento e energia em ocupações que lhes são "próprias", tornaram-se mais vulneráveis ao suicídio. Por outro lado, às mulheres faltariam coragem e força para se suicidar, características estas nelas ausentes por serem constitutivas da esfera do masculino, não do feminino. Dessa forma, pode-se perceber uma tendência: a de pensar o suicídio como uma manifestação essencialmente masculina.

Apesar da constatação acima, é importante notar que a possibilidade de atos, comportamentos e escolhas serem considerados "próprios" de uma determinada esfera, a masculina ou a feminina, é permitida historicamente. Sobre essa questão, as palavras de Rajchaman (1985, p. 64) são importantes, particularmente aquelas que sugerem que o sujeito não é meramente uma condição do saber, que ele não é uma invenção da filosofia, mas uma entidade historicamente construída. Assim, a produção discursiva médica baseada em muitos casos reais, em muitas histórias de homens e mulheres que se suicidavam, permitiu e foi permitida por possibilidades históricas de pensar o suicídio como ato produzido necessariamente pela e na esfera masculina ou feminina.

Para entender melhor a problematização médica sobre as diferenciações sexuais do suicídio, é necessário destacar as escolhas e o uso dos meios utilizados para se dar à morte, peça-chave na constituição do suicídio "masculino" e "feminino", bem como na proliferação de signos de masculinidade e de feminilidade. Em relação aos meios utilizados para provocar o suicídio, os homens prefeririam suicidar-se recorrendo à estrangulação, arma de fogo e às chamadas armas brancas, práticas, aos poucos, vincula- 
das àquelas consideradas masculinas. As mulheres geralmente recusavam as armas brancas e as de fogo, recorrendo de preferência à asfixia por carbono, que as conduzissem, segundo se pensava, a uma morte lenta e doce, características do feminino. Sobre esta idéia de morte lenta e doce provocada pelo carbono, já era sabido naquele período, segundo os próprios médicos, ser um erro profundo, pois acarretava uma morte dolorosa. Contudo, as mulheres consideradas belas preferiam, de acordo com as teses médicas analisadas, a asfixia, o que se justificaria pelo desejo de assim continuar após a morte.

A este respeito, o médico francês Étoc-Demazy (1844, p. 92-97), em seu estudo a partir dos casos de suicídio entre os anos de 1830-1841, adverte que a maior parte dos suicidas utiliza todo tipo de astúcia possível para escapar à vigilância que os ronda. Isso explicaria o fato de os homens, acostumados a carregar armas de fogo para a caça, suicidarem-se no campo. As mulheres, "feitas para a vida doméstica", utilizando astúcia, enviam seus parentes e empregados do lar para fora da casa para cuidarem de seus afazeres. Quando ficam sozinhas, suicidam-se com os meios encontrados em seu próprio espaço, o privado. Dessa forma, explica o fato de $32 \%$ dos suicidas preferirem as armas de fogo para provocar o suicídio e $30 \%$ a submersão, enquanto $58 \%$ das mulheres preferem a submersão e $38 \%$, a suspensão. Quanto ao suicídio provocado por submersão, é necessário sublinhar que os homens afogam-se principalmente nos rios e mares, lugares amplos e carregados de imagens que nos remetem à vastidão, força (das marés, por exemplo) e grandeza, imagens e referências masculinas; já as mulheres lançam-se, de preferência, nos poços de suas próprias casas. Assim, elas não ousariam, com essa escolha, transpor os limites de seu território.

Ainda sobre as diferenças entre os métodos utilizados por homens e mulheres, De Chambre (1884, p. 274-277) sugere que elas não utilizam as armas brancas ou as de fogo, recorrendo preferencialmente à asfixia pelo carbono, que elas acreditam conduzir a uma morte lenta e doce. Preocupadas unicamente com a beleza, enganam-se mais uma vez. Esse engano seria mais recorrente entre as mulheres belas, que desejariam assim continuar depois da morte. Já os homens recorrem, segundo ele, principalmente à estrangulação, à arma de fogo e à arma branca. As mulheres ainda recorreriam ao veneno e à queda de um lugar muito elevado. Vale notar que a opção de pôr fim a seus dias por meio da queda de um lugar muito elevado permite observarmos um paradoxo, afinal estas mulheres que optaram por assim morrer não estariam tão preocupadas com sua beleza e com o estado 
de seu corpo após sua morte, ou não respeitaram os tipos de suicídio e os meios, utilizados para esse fim, que eram considerados "próprios para elas".

De acordo com o médico francês Villette, pode-se explicar a pequena quantidade de suicídios de mulheres pelo fato de seus sentimentos serem menos duradouros do que os dos homens. Elas são pouco accessíveis à intemperança, gozam de uma excitação mais imediata e de uma sensibilidade mais delicada, abandonam-se mais facilmente às impressões vivas que elas recebem. Por essas razões, ele compreende por que elas se tornam habitualmente melancólicas e não suicidas (VILLETTE, 1825, p. 16-17).

O próprio Esquirol, muito conhecidos e citado pelos estudiosos do tema, sugere que, apesar de as mulheres estarem mais expostas às doenças mentais do que os homens, elas suicidam-se bem menos. Isso poderia ser explicado pela moleza de seu caráter e pela timidez que lhes é natural. Pela sensibilidade ser mais exaltada, a imaginação mais aguda, por serem mais vaporosas e nervosas, tornam-se alienadas e loucas, mas não suicidas em proporção aos homens, mais firmes em suas decisões, tornando-se suicidas e não alienados (ESQUIROL, 1989, p. 287).

Dr. Petit (1850, p. 13-15), indica que entre os anos de 1835 e 1846 ocorreram 33.032 suicídios na França. Desse total, mais de 74\% dos casos foram praticados por homens. Algumas considerações foram apresentadas para se explicar os números e as taxas que apontam o maior índice masculino de morte por suicídio:

- As mulheres se exaltam facilmente, agravam seus males, exageram suas dores, mas elas se agarram à vida pelo horror ao sangue, e, quando elas encontram no paroxismo de suas tristezas a força para se suicidar, elas traem suas fraquezas e, num último instinto de coquetterie, preferem os meios menos doloridos e que matam sem desfigurá-las.

A divisão sexual dos papéis que se baseia em "caracteres naturais" e biológicos possibilita e induz a constituição de suicídios considerados próprios aos homens e outros às mulheres, bem como institui formas e maneiras de se suicidar por meios considerados masculinos ou femininos. Mas isso não quer dizer que não havia possibilidades de se confundir, não respeitar ou refazer a fronteira do masculino e do feminino.

No início do século XIX, na França, ocorriam quase 150 suicídios por ano em Paris, em sua maioria por afogamento no Sena. O índice de suicídios dos homens é, segundo Lynn Hunt (1991, p. 44), três vezes superior ao das mulheres. Mas, em todos os casos, o Sena era considerado lugar propício para o ato. 
Littré, em seu Dictionnaire de Médecine (1884, p. 1524), também concorda com os estudiosos do tema. Para ele, suicidam-se três vezes mais homens do que mulheres. A este respeito, Monestier (1995, p. 159) observa que três quartos de suicídios são cometidos por homens. Segundo ele, uma explicação satisfatória é que as mulheres geralmente não desejam o suicídio no sentido de destruição, aniquilamento, pois o que elas querem é "simplesmente" fugir, esquecer, escapar de sua vida presente, dormir, dormir muito e por muito tempo. Dessa maneira, seria possível compreender as razões de elas não se disporem de meios considerados "radicais". Esses meios radicais e violentos seriam características de suicídio masculino.

Assim, estabelece-se que as mulheres não teriam força necessária para o suicídio. Fracas, tornam-se loucas, não suicidas. Os homens, fortes e mais decididos, tornam-se suicidas, utilizando os meios considerados mais violentos.

Concluindo, os discursos que se entrecruzam na tarefa de definir as razões de os homens se suicidarem mais do que as mulheres classificam os atos, os meios e as possíveis causas como próprios de determinado sexo. Assim, estudando e analisando o suicídio de homens, chegava-se a um grupo específico: o suicídio masculino, a formas de se suicidar no masculino; como seu oposto, ao se estudar e analisar os casos de suicídio de mulheres, chegava-se a um outro grupo: o suicídio feminino, a formas de se suicidar no feminino.

Dessa maneira, os discursos médicos que assim classificaram os atos de se dar à morte construíram as diferenças entre o suicídio masculino e o feminino, entre aquele cometido por um homem e o outro cometido por uma mulher. Essa diferenciação ajudou a reforçar a ótica masculina sobre as diferenças sexuais, a assegurar os espaços masculinos de manipulação e controle, definindo, inclusive a própria educação, seus espaços e usos.

\section{REFERÊNCIAS}

ALBUQUERQUE, F. J. F. Monomania - tratamento das moléstias mentaes. Tese (Doutorado em Medicina) - Faculdade de Medicina da Bahia, Salvador, 1858.

BARRETO, J. A. A. B. M. Considerações sobre as principais enfermidades dos homens de Lettras e meios geraes de Hygiena, que lhes dizem respeito. Tese (Doutorado em Medicina) - Faculdade de Medicina do Rio de Janeiro, Rio de Janeiro, 1841. 
DAUMAS, F. C. D. Considération sur le suicide. Tese (Doutorado em Medicina) Faculte de Médecine de Paris, Paris, 1851.

DE CHAMBRE, A. Dictionnaire Encyclopédique des Sciences Médicales. Tome 13, SUE-SYM, Paris, 1884.

D’INCAO, M. A. Mulher e família burguesa. In: DEL PRIORE, M. (Org.). História das mulheres no Brasil. 5. ed. SP: Contexto, 2001.

ENGEL, M. Psiquiatria e feminilidade In: DEL PRIORE, M. (Org.). História das mulheres no Brasil. 5. ed. SP: Contexto, 2001.

ESQUIROL, J.-É.-D. Des maladies mentales. Paris: Frénésie Editions, 1989.

ÉTOC-DEMAZY, G. F. Recherches statistiques sur le suicide, appliquées à l'hygiène publique et la médecine légale. Paris: Germer-Baillière, Libraire-Éditeur, 1844.

GAY, P. A experiência burguesa da Rainha Vitória à Freud: a educação dos sentidos. Trad. Per Salter. SP: Companhia das Letras, 1988.

HAUVILLER, P. Du suicide. Unité de son etiologie - son traitement. Paris: Jouve et Boyer, 1899.

HUNT, L. Revolução Francesa e vida privada. In: PERROT, M. et al. História da vida privada, 4: da Revolução Francesa à Primeira Guerra. Trad. Denise Bottman e Berbardo Joffily, SP: Companhia das Letras, 1991.

LEÃO, G. F. As analogias entre o homem são e o alienado e em particular sobre a monomania. Tese (Doutorado em Medicina) - Faculdade de Medicina do Rio de Janeiro, Rio de Janeiro, 1842.

Le Nouveau Petit Robert. Dictionnaire alphabétique et analogique de la langue française. Nouvelle édition du Petit de Paul Robert. Paris: Dictionnaires Le Robert, 2000.

LITTRÉ, É. Dictionnaire de Médecine, de chirurgie, de pharmacie de l'art vétérinaire e des sciences qui s'y rapportent. 15. édition, Paris: Librairie J.-B. Baillière et Fils, 1884.

MONESTIER, Martin Suicides. Histoire, techniques et bizarreries de la mort volontaire. Des origines á nos jours. Luçon: Le cherche midi éditeurs, 1995.

MORAES, A. J. M. M. Physiologia das paixões e affecções precedida de uma noção philosophica geral e por um estudo aprofundado e descripções anatômicas do Homem e da Mulher. RJ: Dous de Dezembro, 1854.

PETIT, J.-B. Recherches statistiques sur l'étiologie du suicide. Tese (Doutorado em Medicina) - Faculté de Médecine de Paris, França, 1850.

RAGO, M. Do cabaré ao lar: a utopia da cidade disciplinar: Brasil 1890-1930. 3. ed. RJ: Paz e Terra, 1997. 
Descobrindo historicamente o gênero.Cadernos Pagu. Trajetórias do gênero. masculinidades... Publicação do PAGU - Núcleo de Estudos de Gênero/UNICAMP, Campinas, SP, n. 11, p. 89-98, 1998.

RAJCHMAN, J. Foucault: a Liberdade da Filosofia. Trad. Álvaro Cabral. RJ: Zahar, 1985.

RIPA, Y. Le ronde des folles. Femme, folie et enfermement au XIXe siècle (1838-1870). Paris: Aubier, 1986.

SCOTT, J. Gênero: categoria útil de análise histórica. Educação e Realidade, Porto Alegre, v. 16, n. 2, p. 5-22, jul./dez. 1990.

SOIHET, R. História das mulheres. In: CARDOSO, C. F.; VAINFAS, R. (Orgs.). Dominios da História. Ensaios de teoria e metodologia. RJ: Editora Campus, 1997.

STEPHANOU. M. Tratar e curar: discursos médicos nas primeiras décadas do século XX. Tese (Doutorado em Educação) - Faculdade de Educação, Universidade Federal do Rio Grande do Sul, 1999.

TORRES, B. J. R. Dissertação médico-filosófica sobre as causas e sede do suicídio. RJ: Typ. Imnparcial de Francisco de Paula Brito, 1843.

VIANNA, A. F. Considerações hygienicas e médico-legaes sobre o casamento relativamente a mulher. Tese (Doutorado em Medicina) - Faculdade de Medicina do Rio de Janeiro, Rio de Janeiro, 1842.

VILLETTE, A. Du suicide. Tese (Doutorado em Medicina) - Faculdade de Medicina de Paris, França, 1825.

Texto recebido em 13 ago. 2005

Texto aprovado em 14 fev. 2006 